\title{
Analysis of the quality of life of patients with asthma and allergic rhinitis after immunotherapy
}

\author{
Małgorzata Filanowicz'1, Ewa Szynkiewicz'1, Bernadeta Cegła'1 ${ }^{1}$ Zbigniew Bartuzi² \\ ${ }^{1}$ Department of Nursing in Internal Diseases, Collegium Medicum in Bydgoszcz, Nicolaus Copernicus University in Torun, Poland \\ ${ }^{2}$ Chair and Clinic of Allergology, Clinical Immunology and Internal Diseases, University Hospital No. 2, Bydgoszcz, Poland \\ Adv Dermatol Allergol 2016; XXXIII (2): 134-141 \\ DOI: 10.5114/pdia.2015.48061
}

\begin{abstract}
Aim: To assess the quality of life of Polish patients with asthma and/or allergic rhinitis before the implementation and after 30-36 months of immunotherapy.

Material and methods: Two hundred patients have been involved in the study: 101 with allergic asthma and 99 with pollinosis. In order to collect research material, the Polish versions of AQLQ (Asthma Quality of Life) and RQLQ (Rhinoconjunctivitis Quality of Life) questionnaires have been used. The self-administered questionnaires concerned such data as age, sex and the patients' subjective evaluation of their quality of life.

Results: The average increase in quality of life of patients with asthma was 0.84 and of patients with allergic rhinitis -1.50 . A hypothesis was made that changes of quality of life in each examined group differed significantly. A test for two fractions showed that for patients with asthma it was 7.74 and for patients with allergic rhinitis -10.38 . A statistical analysis showed no such relation in the group of patients with asthma (coefficient of correlation $=0.08$ ) and a slight correlation in the group of patients with allergic rhinitis (coefficient of correlation $=0.20$ ). Applied tests did not show any significant differences, which means that an average increase in quality of life does not depend on sex and age of both examined groups.

Conclusions: On the basis of the research conducted among patients before and after a 3-year period of immunotherapy, the following conclusions have been drawn: 1) immunotherapy significantly improves the objective quality of life in both groups; 2) a slight correlation has been identified between the objective and subjective dimension of quality of life amongst patients with asthma, what contributes to a better quality of life; 3) in both study groups, no significant relationship between gender or age and improvement in quality of life has been noted; 4) immunotherapy, from the point of view of the improvement of quality of life, is a valuable therapeutic tool in patients with atopic bronchial asthma and allergic rhinitis.
\end{abstract}

Key words: atopic bronchial asthma, allergic rhinitis, quality of life, subjective and objective quality of life.

\section{Introduction}

An increase in the number of allergy cases, among others bronchial asthma and allergic rhinitis, is not only a reason for perceiving them with reference to social, economic and health problems [1]. More often it is a reason for implementing specific preventive action. It is aimed at early disease detection to reduce troublesome symptoms influencing professional/school productivity, limiting social contacts and medical expenses or frequency of hospital admissions. Global Initiative for Asthma (GINA) recommends 8 aims of the long-term patient care with asthma [2]. Accordingly, action should also be taken to minimize the degree of illness aggravation, unscheduled ad-hoc assistance (of emergency medical services) and the use of rescue medications ( $\beta_{2}$-mimetics). Peak expiratory flow (PEF) and its 24-hour variability should be close to the norm and at the same time minimize undesirable symptoms resulting from pharmacotherapy. Exploration of the inflammatory basis of asthma and implementation of appropriate treatment has resulted in reducing problems caused by illness and increasing daily activity. Implementation of appropriate anti-inflammatory therapy reduces disease symptoms and gives an opportunity of better physical and psy-

Address for correspondence: Małgorzata Filanowicz PhD, Department of Internal Nursing, Collegium Medicum, Nicolaus Copernicus University, 3 Techników St, 85-801 Bydgoszcz, Poland, phone: +48 501601 780, e-mail: gosiafilanowicz@cm.umk.pl Received: 30.04.2014, accepted: 10.10.2014. 
chological functioning and reduces the financial burden on the state e.g. sickness benefits. For that purpose, international guidelines have been drawn up for general practitioners (GPS) to optimize their preventive actions directed at patients suffering from allergies. However, in spite of all efforts, these illnesses are still recognized too late and are confused with chest infections and not always treated in an appropriate way [3].

\section{Aim}

The purpose of this study is to assess the quality of life of patients with asthma and/or allergic rhinitis before implementation and after 30-36 months of immunotherapy. Symptoms of allergies can cause great discomfort in patient's everyday functioning: in performing a satisfactory role in family, professional and social life. It is essential to find out these factors and identify determinants which have positive effects on patient's standard of living.

\section{Material and methods}

Two hundred patients have been involved in the study, both men and women aged 18-60 years. They were divided into two subgroups. The study group comprised patients with asthma or allergic rhinitis diagnosed on the basis of symptoms described, an interview, a hearing test, positive bronchial challenge test, spirometric examination and positive history of histamine provocation, and after clinical evaluation by a doctor, they were subjected to immunotherapeutic treatment. Patients who had already undergone desensitization, patients who were desensitized because of oversensitivity to hymenoptera venom and those who did not meet the age requirements determined in the study have been excluded from the research group.

The research was conducted in 2005-2009 in allergy clinics in Bydgoszcz at the following facilities: 10 Military Clinical Hospital with Polyclinic, Dr Jan Biziel University Hospital No. 2, Kuyavia and Pomerania Pulmonology Center and Dr. E. Warminski Municipal Hospital.

The division into stages and the time between the first and second examination resulted in exclusion of some patients from the research group. These were mainly patients who in the course of examination stopped their treatment or did not agree to take part in the second stage of examination. As a result, 101 patients with atopic asthma and 99 with allergic rhinitis took part in the research.

\section{The research tool}

In order to collect research material, Polish versions of AQLQ and RQLQ standardized questionnaires have been used. These are research tools designed to test adults used in European and American countries in order to determine quality of life of patients with allergic asthma and allergic rhinitis. The use of both Polish versions of the questionnaires has been validated. The author of the aforementioned tools - Professor Elizabeth Juniper from Mc Master University in Canada - gave permission to use both questionnaires.

With the use of questionnaires, the influence on everyday activity of symptoms of the illness and determining quality of life has been examined. The RQLQ research tool consists of 28 questions and deals with seven areas of life which are most essential to the patient: everyday activity, sleep, symptoms not related to hay fever, practical problems, nasal symptoms, ocular symptoms and emotional problems. The patient described each symptom and activity using a scale depending on the degree in which he or she finds it troublesome and limits his or her functioning. Symptoms were rated as non-troublesome, fairly troublesome, quite troublesome, definitely or extremely troublesome. The AQLQ research tool consists of 32 questions. It deals with four main domains (areas) of life for patients suffering from asthma: symptoms, limitations on activity, emotional functioning and environmental stimuli affecting quality of life.

Each respondent answered specific Likert scale questions and marked appropriate points on a scale from 1 to 7 in the AQLQ questionnaire. Maximum values meant a better situation. A post treatment increase in score by 0.5 was recognized as clinically significant. The AQLQ questionnaire is characterized by the greatest accuracy since when drawn up it was consulted with patients, members of their families most affected by the illness (in physical, psychological and social aspects) and perhaps also with specialists in a given field [4].

In the RQLQ questionnaire answers were marked on a scale from 0 to 6 , however in this instance, the higher score indicated a worse sense of well-being. Every respondents' scores were added up and then average values were calculated which were integrated parameters assessing the condition of the patient in a given category. A change compared to the initial value by at least 0.5 point was considered significant. Lack of improvement was considered to be a therapeutic failure [5].

A self-administered questionnaire concerned demographic data such as age, sex and education. The second part of the questionnaire concerned subjective evaluation of quality of life. Statistical analysis of examinations was conducted based on a number of tests.

\section{Statistical analysis}

A parametric test was used to verify hypotheses for two rates of the structure, the Shapiro-Wilk nonparametric test, Snedecor's F test. Parametric t-tests were used to compare average values in groups where the norm of distribution was established with the Shapiro-Wilk test. In cases of homogeneity of variance in compared groups, verification of the hypothesis on equality of averages was 
made with the use of the Student's $t$-test. When this condition was not met (variances turned out to be different), a modified Cochran and Cox t-test was used. Parametric z-test based on normal distribution was applied in order to compare average values in two attempts with sufficiently large numbers. In order to establish a correlation between features, Pearson's linear correlation coefficient was calculated and verified with the use of the Student's t-test. In cases of normal distribution of examined features and homogeneity of variance, a one-way analysis of variance ANOVA parametric test was applied comparing average values in more than two groups. The Kruskal-Wallis nonparametric test was used in order to compare distribution of examined features in more than two groups, the Bartlett's parametric test comparing variances in more than two groups and a nonparametric $\chi^{2}$ test in order to find out possible relations between non-measurable features (quality).

\section{Test characteristics}

The research group comprised people considered by the doctor for immunologic treatment on the basis of laboratory test results, evaluation of skin test results and gravity of symptoms. The research group comprised patients with a distinct disease entity, however selection to the group took place on a random basis.

Among research groups of patients with asthma and allergic rhinitis, women constituted the largest percentage of $55.4 \%$ and $57.6 \%$, respectively.

In the group with asthma, patients aged from 31 to 40 constituted the largest percentage (31.7\%). However this result only slightly differed from those described as younger, where this percentage was $30.7 \%$. In the group of patients with allergic rhinitis there were most cases of illness in the $18-30$ age group (44.4\%). On the basis of analysis with the use of $z$-test, the average age was calculated for patients with asthma which was $36.9 \pm 10.6$ and for patients with allergic rhinitis $34.3 \pm 10$. .

\section{Analysis of research findings}

The research enabled collection of data about quality of life of patients with asthma and patients with allergic rhinitis. AQLQ and RQLQ questionnaires and the Author Interview Questionnaire provided the basis for the research. For that purpose, questionnaire forms were distributed, in which the respondents marked their answers to questions on a scale from 1 to 7 . Higher values meant a better frame of mind related to a higher quality of life in a given category. The AQLQ questionnaire form was distributed among patients with asthma. It contained 32 questions however patients with allergic rhinitis filled the RQLQ questionnaire form by answering 28 questions (in the RQLQ questionnaire, the scale of 0-6 was substituted for 7-1). Evaluation of quality of life of every patient was calculated as the average of all points gained for every response. The greater the average value, the higher the quality of life of a given patient.

Such evaluation of quality of life may be considered objective since for every patient, evaluation of quality of life was estimated on the basis of dozens of replies.

Analysis was done in stages. In the first stage global quality of life of patients was calculated in both research groups before implementation of immunotherapy $\left(Q_{\text {before }}\right)$ and in the period of 36 months after treatment $\left(\mathrm{QOL}_{\text {after }}\right)$. Then, improvement in quality of life of all patients was estimated and an increase in quality of life described (IQoL). Results were given in numerical form. Higher results corresponded with a greater increase. Results obtained in the research were compared in both research groups and differences were estimated. In order to determine a correlation between sociodemographic factors, an average increase in quality of life was compared to data from the Author Interview Questionnaire. In order to determine objective and subjective quality of life, patients' opinions and results of standardized questionnaires were compiled and compared between both research groups.

After 3 years, changes in quality of life for patients who had undergone immunotherapy was further reviewed. In order to state what changes in quality of life took place, another questionnaire was conducted where patients answered the same questions.

In the next stage a difference between assessment of quality of life after treatment and before treatment was calculated for every patient: $I Q O L=Q 0 L_{\text {after }}-Q_{\text {Q }} L_{\text {before }}$. The IQoL positive value meant an increase in quality of life, however negative scores indicated that the patient perceived his quality of life as having deteriorated post treatment.

\section{Global quality of life of patients with asthma and allergic rhinitis before and after immunotherapy}

All patients from both groups were subjected to global assessment before the start of immunotherapeutic treatment and after 30-36 months of its implementation. Average global quality of life scores were calculated from all replies included in standardized AQLQ and RQLQ questionnaires adjusted to a given disease entity.

A hypothesis assuming that an average increase in quality of life in both groups is essential, i.e. indeed differs from zero, was also verified. For that purpose a parametric $t$-Student test was applied for dependent groups. Results shown in Table 1 show that an average increase in both groups is positive and indeed differs from zero. It means that in both groups, a significant improvement in quality of life took place after immunotherapy.

In order to compare average increases in quality of life, $z$-test based on normal distribution was applied. According to the central border statement, the use of this test was justified because of large numbers of compared 
Table 1. Average increase in quality of life of patients with asthma and allergic rhinitis

\begin{tabular}{|c|c|c|c|}
\hline Parameter & & $\begin{array}{c}\text { Patients } \\
\text { with asthma }\end{array}$ & $\begin{array}{l}\text { Patients with } \\
\text { allergic rhinitis }\end{array}$ \\
\hline$N$ & & 101 & 99 \\
\hline Min. & & -1.63 & -1.54 \\
\hline Max. & & 3.69 & 6.25 \\
\hline $\begin{array}{l}\text { Average increase } \\
\text { in quality of life }\end{array}$ & & 0.84 & 1.50 \\
\hline SD & & 1.10 & 1.58 \\
\hline \multirow{2}{*}{$\begin{array}{l}T \text {-Student test } \\
\left(t_{c r}=1.98\right)\end{array}$} & $t$ & 7.62 & 9.44 \\
\hline & $p$ & $<0.0001$ & $<0.0001$ \\
\hline
\end{tabular}

groups. The test showed significant differences. The value of calculated z-statistics was 3.45 and is greater than 1.96 critical value taken from the table of normal distribution $(p<0.0006)$. Therefore, the average increase in quality of life after treatment is significantly greater in the group of patients with allergic rhinitis than in the group of patients with asthma (Table 2).

Differences which occurred after implementation of immunotherapy in both research groups were also assessed. Statistical analysis of data obtained from examinations was conducted in order to compare quality of life before implementation and after completion of immunotherapeutic treatment. Cases of increase and decrease in quality of life in the group of patients with asthma and allergic rhinitis were counted. A hypothesis was verified that changes in quality of life in each research group differed significantly. For that purpose a test was applied for two fractions (test for two rates of the structure). Results of calculations and tests are shown below.

Increase in quality of life which was established on the basis of a great number of answers received as a result of the survey was regarded as objective. Respondents simultaneously answered a question about how much quality of life changed after immunotherapy by marking one of 5 replies on a scale from 0 (did not change at all) to 4 (to a high degree). Such evaluation can be considered as subjective. On the basis of results it was established whether there is any correlation between objective and subjective assessment of quality of life of patients. For that purpose, Pearson's correlation coefficients were calculated and verified (Table 3).

Another stage is an attempt to find a possible correlation between increase in objective quality of life and subjective evaluation of quality of life done by the patient. This procedure was performed in order to find out whether there is any relationship between the objectively assessed increase in quality of life and subjective evaluation. Statistical analysis showed lack of such a relation in the group of patients with asthma (coefficient of correlation $=0.08$ ) and a slight correlation in the group of patients with allergic rhinitis (coefficient of correlation $=0.20$ ) (Figure 1 ).
Table 2. Changes in quality of life of patients with asthma and allergic rhinitis

\begin{tabular}{lccc}
\hline Changes in quality of life & Asthma & $\begin{array}{c}\text { Allergic } \\
\text { rhinitis }\end{array}$ \\
\hline Negative (increase in quality of life) & $23(22.8 \%)$ & $13(13.1 \%)$ \\
\hline Positive (decrease in quality of life) & $78(77.2 \%)$ & $86(86.9 \%)$ \\
\hline Total & $101(100 \%)$ & $99(100 \%)$ \\
\hline Test for two fractions & $u$ & 7.74 & 10.38 \\
\cline { 2 - 4 } & $p$ & $<0.0001$ & $<0.0001$ \\
\hline
\end{tabular}

Table 3. Correlations between objective and subjective assessment of quality of life

\begin{tabular}{lccc}
\hline Parameter & $\begin{array}{c}\text { Group of patients } \\
\text { with asthma } \\
(n=101)\end{array}$ & $\begin{array}{c}\text { Group of patients } \\
\text { with allergic } \\
\text { rhinitis }(n=99)\end{array}$ \\
\hline Coefficient $R_{x y}$ & 0.08 & 0.20 \\
\hline $\begin{array}{l}T \text {-Student } \\
\text { test } \\
\left(t_{c r}=1.98\right)\end{array}$ & $t$ & 0.80 & 2.01 \\
\cline { 2 - 4 } & $p$ & $0.43(\mathrm{NS})$ & $<0.05$ \\
\hline
\end{tabular}

Using gathered data, actions aimed at establishing the QOL connection with given sociodemographic factors were taken. The first analyzed factor was the sex of respondents.

In order to compare the average increase in quality of life, parametric t-Student and Cochran-Cox tests were applied. Application of parametric tests was possible due to the fact that Shapiro-Wilk test did not reject the hypothesis of normal distribution of increase in quality of life $(\mathrm{QOL})$ of men in both groups. Verification of the hypothesis on normalcy distribution of QOL in women was not necessary due to numbers which were large enough ( $n>50)$. In the case of different variances (F-Snedecor test) Cochran-Cox test was applied to compare average results whereas when variances did not differ significantly - Student's t-test was used.

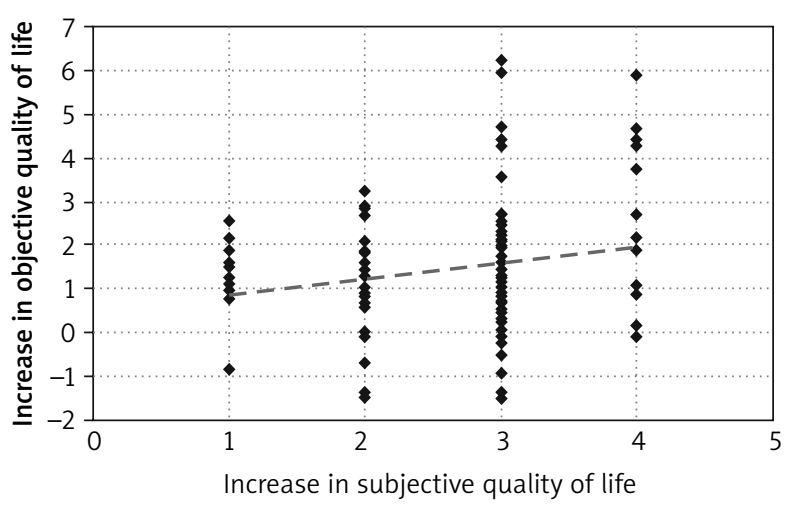

Figure 1. Comparison of objective and subjective quality of life of patients with allergic rhinitis 
Table 4. Increase in quality of life of patients with asthma depending on age

\begin{tabular}{|c|c|c|c|c|c|}
\hline \multirow[t]{2}{*}{ Parameter } & & \multicolumn{4}{|c|}{ Age } \\
\hline & & $18-30$ & $31-40$ & $41-50$ & $51-60$ \\
\hline$N$ & & 31 & 32 & 26 & 12 \\
\hline Min. & & -1.63 & -1.59 & -0.91 & -0.91 \\
\hline Max. & & 3.69 & 3.66 & 2.66 & 3.09 \\
\hline Average & & 0.76 & 0.99 & 0.66 & 1.03 \\
\hline SD & & 1.12 & 1.13 & 1.03 & 1.18 \\
\hline \multirow[t]{3}{*}{ Shapiro-Wilk normality test } & W & 0.986 & 0.996 & 0.946 & 0.971 \\
\hline & $W_{k r}$ & 0.929 & 0.930 & 0.920 & 0.859 \\
\hline & Normality & Yes & Yes & Yes & Yes \\
\hline \multirow[t]{2}{*}{ Bartlett's test $\left(\chi_{c r}^{2}=7.81\right)$} & $\chi^{2}$ & \multicolumn{4}{|c|}{0.37} \\
\hline & $p$ & \multicolumn{4}{|c|}{0.95 (NS) } \\
\hline \multirow[t]{2}{*}{ ANOVA test $\left(F_{c r}=2.70\right)$} & $F$ & \multicolumn{4}{|c|}{0.60} \\
\hline & $p$ & \multicolumn{4}{|c|}{0.62 (NS) } \\
\hline
\end{tabular}

Applied tests did not show any significant differences, which means that average increases in quality of life of women and men do not differ considerably in both groups. Therefore, there is no relation between an increase in quality of life and sex.

Another analyzed factor was age. The connection between QOL and age was examined in both research groups, i.e. patients with asthma and patients with allergic rhinitis.

Respondents in both groups were divided into 4 subgroups: $18-30$ years, $31-40$ years, $41-50$ years and $51-60$ years.

The aim of this part of the research was to compare the increase in quality of life within three years of indi- vidual age brackets of both groups. For that purpose, in every subgroup, average values and QOL standard deviations were described. With the use of Shapiro-Wilk test it was established that QOL distributions in compared age subgroups do not differ significantly from normal distribution. It was also estimated, with the use of Bartlett's test, that variances in a group of patients with asthma are homogeneous. Therefore, the application of ANOVA analysis of variance test was possible. However in a group of patients with allergic rhinitis variances turned out to be different. Therefore, additionally the Kruskal-Wallis nonparametric test was used in order to compare QOL distributions. Test results are presented in the following tables (Tables 4 and 5).

Table 5. Increase in quality of life of patients with allergic rhinitis depending on age

\begin{tabular}{|c|c|c|c|c|c|}
\hline \multirow[t]{2}{*}{ Parameter } & & \multicolumn{4}{|c|}{ Age } \\
\hline & & $18-30$ & $31-40$ & $41-50$ & $51-60$ \\
\hline$N$ & & 44 & 25 & 21 & 9 \\
\hline Min. & & -1.39 & -1.46 & -1.54 & 0.32 \\
\hline Max. & & 6.25 & 5.94 & 2.82 & 3.57 \\
\hline Average & & 1.54 & 1.89 & 0.90 & 1.67 \\
\hline SD & & 1.67 & 1.91 & 0.91 & 1.04 \\
\hline \multirow[t]{3}{*}{ Shapiro-Wilk test for normality } & $W$ & 0.957 & 0.961 & 0.953 & 0.962 \\
\hline & $W_{k r}$ & 0.944 & 0.918 & 0.908 & 0.829 \\
\hline & Normality & Yes & Yes & Yes & Yes \\
\hline \multirow[t]{2}{*}{ Bartlett's test $\left(\chi_{\mathrm{cr}}^{2}=7.81\right)$} & $\chi^{2}$ & \multicolumn{4}{|c|}{12.81} \\
\hline & $p$ & \multicolumn{4}{|c|}{0.01} \\
\hline \multirow[t]{2}{*}{ ANOVA test $\left(F_{c r}=2.70\right)$} & $F$ & \multicolumn{4}{|c|}{1.57} \\
\hline & $p$ & \multicolumn{4}{|c|}{0.20 (NS) } \\
\hline \multirow[t]{2}{*}{ Kruskal-Wallis test $\left(H_{c r}=7.81\right)$} & $H$ & \multicolumn{4}{|c|}{4.34} \\
\hline & $p$ & \multicolumn{4}{|c|}{0.23 (NS) } \\
\hline
\end{tabular}


Applied tests did not show any relation between increase in quality of life and age in both groups. It means that the average quality of life in individual age groups do not differ significantly.

\section{Discussion}

Quality of life depends on a number of factors. When a patient is informed of the diagnosis he or she often has to change his or her lifestyle. It is usually connected with total change in the professional life or the way of spending leisure time. The time between diagnosis and acceptance of the illness varies in length for individual patients. At that time, adaptation to information provided by medical staff can be better or worse. Rejection of the illness and lack of knowledge about it cause gradual deterioration in the medical condition and greater restrictions in everyday life. Therefore, quality of life is not on a desirable level. Accepting the course of treatment is another important matter. The need for a long-term systematic medicine intake may be connected perhaps with non-compliance with medication taking, especially at the beginning of treatment and failure to attend doctor's appointments. The patient rejects the fact of chronic disease because he is afraid of stigmatization and of being labeled a sick person. For this reason, providing information about the diagnosis should be adapted to the current emotional state of the patient, his or her ability to assimilate and understand the information. Such an attitude is essential for the patient in order to aptly deal with stress caused by the diagnosis of a chronic disease. Such widely understood professionalism can contribute not only to the effectiveness of drug treatment, but also to desired functioning in the psychological sphere, and as a result, to better quality of life. Quality of life also means the possibility of carrying out one's plans, self-realization, relaxation and life in society. Activity in all these areas contributes to the feeling of high-level quality of life. If self-realization is impossible the patient has the feeling of poor quality of life.

In this research, quality of life was analyzed in patients with asthma and allergic rhinitis before and after 36 months of immunotherapeutic treatment. Results obtained from standardized AQLQ and RQLQ questionnaires allow us to state that there is an increase in quality of life perceived in both examined groups. During the first examination, which took place before the beginning of immunotherapy, quality of life was determined and in patients with asthma it was 4.55 and in those suffering from allergic rhinitis 3.79. In turn, after about 3 years of immunotherapeutic treatment, quality of life of patients with asthma increased by 0.84 , and in patients with allergic rhinitis by 1.50 . It means that in spite of heavy psychological stress, which can develop into a chronic state with subsequent consequences, involvement in therapy enables stabilization of medical condition(s).
In the research conducted by Modrzyński concerning the influence of immunotherapy on improvement of quality of life for patients suffering from allergic rhinitis, a positive therapeutic effect was obtained in $80 \%$ of respondents. In addition, quite an important difference was noticed between the first $(3.6 \pm 0.9)$ and the second examination $(1.9 \pm 1.2)$ [16]. Results are significant because the study was conducted over a similar period of time and the same research tool was used. Also, positive results reducing clinical symptoms of allergic rhinitis were obtained by Hofman during immunotherapeutic treatment in the Center of Allergology in Poznan. It showed that after 3 years of desensitizing using the all-year-round method, symptoms of bronchial asthma and allergic rhinitis considerably disappeared in $51.7 \%$ of patients. After extending immunotherapy to 4 years, the number of people with clinical improvement grew to $89.6 \%$. In order to obtain positive effects of treatment in the remaining patients (10.4\%), the period of treatment was extended by 2 more years [7]. Amongst patients suffering from allergic rhinitis, foreign researchers such as Adelroth et al. [8] also achieved results confirming improvement of quality of life. Walker in her research compared the group with ANN treated with immunotherapy to a group treated with placebo. Achieved results allowed to propose that the therapy considerably contributed to reduction of symptoms associated with rhinitis (49\%) in comparison with an untreated group (15\%). Therefore, it is possible to state that the treatment considerably contributed to improvement of the quality of life of patients [9].

The therapy positively influenced the objective assessment of patients in both examined groups. Immunotherapeutic treatment considerably contributed to improvement of quality of life. However, in both examined groups, i.e. patients with asthma and patients with allergic rhinitis, a difference between changes in quality of life was noticed. Better results were achieved in the group of patients with allergic rhinitis. Generalization of the subject concerning quality of life allowed for comparison of its objective and subjective aspects. The results indicate that in spite of improvement of the medical condition, which increase in quality of life after immunotherapy was shown, AQLQ and RQLQ questionnaires showed that only a group of patients with allergic rhinitis manifested a better sense of well-being. It was shown that along with an increase in objective quality of life, patients demonstrate higher subjective evaluation of their medical condition (coefficient of correlation $=0.20$ ). In the group of patients with asthma no such a relation was noted (coefficient of correlation $=0.08$ ). It may result from the fact that efforts based on effective management of stressful situations such as symptoms of allergic rhinitis or asthma greatly differ and limit daily activity to a different degree. 
However, in Bousquet's research, immunotherapy positively influenced not only the medical condition but also contributed to better subjective evaluation [10].

Weinert claims that subjective feelings are a part of every human, irrespective of sex. In his view, the quality of life reflects the degree of self-realization for each of us [11].

Whereas Meyza suggests that there are significant differences in evaluation of quality of life between a group of men and a group of women. Women usually more often and longer dwell on negative aspects of life. In turn, men have a more positive attitude to life finding more joy in it. Therefore, it is claimed that average quality of life of women is lower than quality of life of men [12].

In foreign literature there are a lot of sources concerning asthma and allergic rhinitis describing them as medical cases and dealing with the importance of research on patients' quality of life. Unfortunately, there is little research on the influence of sociodemographic factors on quality of life of patients with asthma and allergic rhinitis. However, assumptions presented by Meyza can be found in Dorner's work who obtained worse results for females $(21.8 \%$ vs. $15.2 \%, p<0.05)$ during evaluation of quality of life for patients with asthma [13]. In addition, in research presented by Ferreira, there is a note on a correlation between quality of life and sex. It was shown that men were characterized by a lower level of restrictions because of asthma than women [14].

Results presented in this study do not confirm the aforementioned assumption. In conducted research there is no significant relation between quality of life and sex of respondents both in the group of patients with asthma ( $p=0.31)$ as well as the one with allergic rhinitis $(p=0.06)$. Even though it is possible to observe a greater increase in quality of life of women in the group with asthma, applied tests excluded such a relationship.

In further research an attempt was made to establish how much age influences evaluation of quality of life. On the basis of an analysis with the help of Z-test, an average value of age was obtained for patients with asthma (36.9 $\pm 10.6)$ and for patients with allergic rhinitis $(34.3 \pm 10.8)$. Compared with the age group (average 51.6) of patients taking part in the research by Uchmanowicz et al., it is a relatively young population [6].

In some publications authors prove that the stage of life at which a given patient currently is affects an overall view of quality of life. According to these authors, the greatest optimism and better state of well-being are characteristic of young and elderly people. Middleaged patients are in a group that evaluates their quality of life on the lowest level [15]. Statistical analysis of research did not confirm this opinion. It was not demonstrated that age reduced quality of life. However, in spite of lack of a statistical significant difference, there is some disproportion. Patients with allergic rhinitis, in the 41-50 age group, show a minimally lower increase in quality of life than those in other age subgroups. Perhaps this minor difference is caused by the small number of people in a given research group. On the other hand, it is possible to agree with the theory of Bee who thinks that the stage of middle adulthood does not bring so many new challenges. It is the time to fulfill roles which people started to play in early adulthood. Perseverance to achieve one's goals falls down whereas flexibility to realize one's ambitions increases [16]. Yet, according to Erikson, middle-aged people, irrespective of sex, are able to be truly creative using their experience and productivity. If these abilities are not used, the patient will be condemned to stagnation. Each patient in this age bracket should present emotional and intellectual maturity for creation, in this case the ability to accommodate oneself to living with an illness. Knowledge gained during one's life, abilities and experience should be sufficient enough to be able to fulfil mature and responsible aims [17].

According to Nęcka, maturity in action is acquired from a few up to a dozen years. It results from the fact that in order to deal with and manage important problems it is necessary to master a given subject. It means that it is necessary to become an expert in a given field, which is time-consuming [18]. These theories are justified by the work of $\mathrm{Ho}$ and Jones who proved that in $\mathrm{pa}-$ tients with asthma, age was a crucial factor influencing an increase of depressive symptoms and reluctance to take action. In fact, scientists examined asthmatic patients who had already been suffering from the illness for a few years and noticed a larger percentage of elderly women who were discouraged from taking action in the postmenopausal period.

It is possible to conclude that younger women, in spite of troublesome symptoms, have greater adaptive abilities allowing them to be more optimistic. At the same time, a similar relation was not observed in men [19]. Nowobilski et al. obtained similar results in research conducted at Polish centers [20]. Also at the Wrocław center, in research by Uchmanowicz, quality of life of patients with asthma appears to decrease with age. In these examinations the border of decrease in satisfaction was established at the age of 50, therefore this can also be described as the postmenopausal age. Similar results were obtained by Oğuztürk et al., Hazell et al. who also showed a decrease in quality of life of asthmatic patients with age [21, 22]. Whereas in research by Ferreira et al. conducted in Portugal, the highest quality of life was noticed in younger patients [14].

\section{Conclusions}

On the basis of research conducted in a group of patients before and after completing a 3-year period of immunotherapy, the following conclusions were drawn:

Immunotherapeutic treatment affects the improvement of objective quality of life of patients to a great 
degree in both groups. In a group of patients with allergic rhinitis immunotherapy improves quality of life to a greater degree than in a group of patients with asthma.

There is a slight relationship between the objective and subjective aspects of quality of life among patients with asthma, which results in better overall quality of life.

No significant correlation between sex and age of examined people and the improvement of quality of life has been found.

Immunotherapy, when taking the improvement of quality of life into account, is a valuable therapeutic method for patients with atopic bronchial asthma and allergic rhinitis.

\section{Conflict of interest}

The authors declare no conflict of interest.

\section{References}

1. Rutkowski K, Sowa P, Rutkowska-Talipska J, et al. Allergic diseases: the price of civilisational progress. Postep Derm Alergol 2014; 31: 77-83.

2. Erikson EH. Dzieciństwo i społeczeństwo. Dom Wydawniczy Rebis, Poznan 1997.

3. Kruszewski J. Simplification of asthma control estimation. Asthma Control Test (ATC). A Guide for GPs. 2007; 10: 21-4.

4. Gerlach FM, Beyer M, Muth C, et al. New perspectives in the primary care of the chronically ill-against the "tyranny of the urgent”. Z Arztl Fortbild Qualitatssich 2006; 100: 335-52.

5. Modrzyński M, Zawisza E. The results of diagnostic tests in patients with pollinosis treated by allergen immunotherapy. Asthma Allergy Immunol 2005; 10: 154-61.

6.Uchmanowicz I, Jankowska B, Panaszek B, Fal AM. Wpływ czynników społeczno-demograficznych na jakość życia chorych na astmę oskrzelowa. Alergologia Info 2010; 5: 57-65.

7. Hofman T. Immunoterapia całoroczna preparatem Alergovit. Alergol Współcz 2001; 1: 9-12.

8. Adelroth E, Haahtela T, Haahtela T, et al. Recombinant humanized mAb-E25, an anti-lgE. in birt pollen-inducated seasonal allergic rhinitis. J Allergy Clin Immunol 2000; 106: 253-9.

9. Walker S, Pajno G, Lima MT, et al. Grass pollen immunotherapy for seasonal rhinithis and asthma: a randomized controlled trial. J Allergy Clin Immunol 2001; 107: 67-93.

10. Bousquet J, Scheinmann P, Guinnepain MT, et al. Sublingualswallow immunotherapy (SLIT) in patients with asthma due to house-dust mites: a double blind, placebo-controlled study. Allergy 1999; 54: 249-60.

11. Wejnert B. Problematyka subiektywnej i obiektywnej oceny jakości życia w badaniach amerykańskich. In: Jak żyć? Wybrane problemy jakości życia. Wachowiak A (ed.). Wyższa Szkoła Pedagogiczna im. Tadeusza Kotarbińskiego w Zielonej Górze, Poznan 2001; 97-112.

12. Meyza J. Jakość życia w chorobie nowotworowej. Centrum Onkologii Instytutu im. Marii Skłodowskiej-Curie w Warszawie, Warsaw 1997.

13. Dorner T, Muller HK, Schmidl H, et al. Subjective health and impaired quality of life due to allergies in a representative population survey. Wien Med Wochenschr 2007; 157: 243-7.

14. Ferreira LN, Brito U, Ferreira PL. Quality of life in asthma patients. Rev Port Pneumol 2010; 16: 23-55.
15. Glise H, Wiklund I. Quadrennial Review. Health-related quality of life and gastrointestnal disease. J Gastroenterol Hepatol 2002; 17: 72-84.

16. Bee H. Psychologia rozwoju człowieka. Wydawnictwo Zysk i S-ka, Poznań 2004

17. Chmielewska-Szewczyk D. Alergia ujawnia się już we wczesnym dzieciństwie. Alergia 2009; 2: 5-10.

18. Nęcka E. Psychologia twórczości. Gdańskie Wydawnictwo Psychologiczne, Gdansk 2003.

19. Ho SF, Jones D. Morbidity in older people with self-reported asthma. Age Ageing 1999; 28: 475-80.

20. Nowobilski R, de Barbaro B, Furgat M. Analysis of depression in patients with bronchial asthma. Allergy Asthma Immunol 2002; 7: 211-5.

21. Hazell M, Frank T, Frank P. Health related quality of life in individuals with asthma related symptoms. Respir Med 2003; 97: 1211-8.

22. Oğuztürk Ö, Ekici A, Kara M, et al. Psychological status and quality of life in elderly patients with asthma. Psychosomatics 2005; 46: 41-6. 